\title{
Climate change: things we can do
}

\author{
Fiona Godlee editor, The BMJ
}

Those of us who've been banging on about the threat of climate change to human health for longer than we care to remember should take heart. Hot on the heels of the Pope's encyclical on the environment, we have an encyclical of a different kind, from the Lancet Commission on Health and Climate Change.

Pope Francis's intervention is as unusual as it is welcome (http: //bit.ly/1duI5vP). While previous papal encyclicals have been directed mainly at Roman Catholics, Pope Francis seeks to "enter into a dialogue with all people about our common home." Basing his strongly worded comments explicitly on environmental science, he says that "the planet is reaching breaking point" and urges courageous action by governments and international bodies to slow down and reverse global warming, protect the rainforests, and ensure that everyone in the world has access to clean water.

Because of its opposition to contraception the Catholic church is not without its critics. Perhaps unsurprisingly, the Pope makes no concession on population control, putting the blame for catastrophic environmental degradation firmly at the door of unequal and excessive global consumption and waste. But population growth is listed among the underlying causes of climate change in the Lancet Commission's report, along with increasing consumption and the growing carbon intensity of development (www.thelancet.com/commissions/climatechange).

The Lancet Commission's report, careful in its planning and ambitious in scope, should help to shift the debate away from further rehearsals of the evidence on climate change, towards much needed solutions. Where its earlier 2009 report positioned climate change as the greatest threat to public health in the $21 \mathrm{st}$ century (www.thelancet.com/series/health-and-climate-change), the new report presents dealing with climate change as our greatest public health opportunity. As well as tackling the threats to human survival from severe weather events, conflict, and population displacement, a low carbon emission world promises a healthier, more active population and a more equitable society.

The report outlines what policy makers and governments need to do: establish carbon pricing, quickly phase out coal powered energy, move towards sustainable cities, take account of health when making decisions, and invest in public health research, monitoring, and surveillance.

But time is short. As reported in an editorial this week (doi:10. 1136/bmj.h3196) and previously explained in a BMJ Analysis "What every doctor should know" article on the science of climate change (doi:10.1136/bmj.g5178), there is a consensus that greenhouse gas concentrations need to stop rising within about 23 years if we are to avoid global temperature rises of more than $2^{\circ} \mathrm{C}$.

What Pope Francis describes as the "immensity and urgency of the challenges we face" should force us to be clear about where we should place our efforts. The Lancet Commission encourages health professionals to be active as role models and advocates for behaviour and policy change.

Our editorial and an open letter in the Guardian (http://bit.ly/ $1 \mathrm{GMlHGH}$ ) call for divestment from fossil fuel companies and re-investment in renewable energy (doi:10.1136/bmj.h3436). The BMA and more than 200 institutions have committed themselves to this action. The Wellcome Trust and the Bill and Melinda Gates Foundation are the world's two largest health charities. On the grounds that it is wrong to profit from an industry whose core business threatens human and planetary health, they should now do the same.

Cite this as: BMJ 2015;351:h3591

๑ BMJ Publishing Group Ltd 2015 